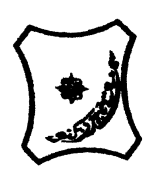

Bayero Journal of Pure and Applied Sciences, 12(1): 24 - 30

ISSN $2006-6996$

\title{
PHOTODEGRADATION OF RHODAMINE B USING Cd-AI/C DOUBLE LAYERED HYDROXIDE CATALYST
}

\author{
Muhammad, A.S. and *Garzali, F. A. \\ Department of pure and Industrial chemistry Bayero University Kano Nigeria \\ Email: asmuhammed.chm@buk.edu.ng Tel: 08186615765
}

\begin{abstract}
This paper presents the degradation of Rhodamine B using cadmium aluminium carbon (Cd-Al/C) catalyst under visible light. The layered double hydroxide was successfully prepared from cadmium fluoride $\left(\mathrm{CdF}_{2}\right)$, aluminium chloride $\left(\mathrm{A} / \mathrm{Cl}_{3}\right)$, and rice husks activated carbon, and then characterized by X-ray Diffaraction (XRD) Scaning Electron Microscopy (SEM) and Fourier Transform Infrared (FTIR) methods. The peaks at $2 \theta$ 23.4 and 35.5 in the XRD result confirmed the presences of $\angle D H$. The effect of contact time, catalyst dosage, $\mathrm{pH}$ and initial concentration, on the photo degradiation of Rhodamine $B$ were investigated. The experimental results showed that after $100 \mathrm{~min}$ visible light irradiation, the percentage degradation using $200 \mathrm{mg} C \mathrm{Cd}-\mathrm{Al} / \mathrm{C}, \mathrm{pH} 7$ and 3 ppm Rhodamine $B$ concentration reached to $76.22 \%$. For kinetics studies the data obtained were analysed using pseudo first order and pseudo second order kinetic models. From the linear regression coefficient values the data were found to be best fitted to pseudo second order kinetics. The results revealed that the $C d-A l / C$ show good catalytic
\end{abstract} activity.

Key words: Layered Double Hydroxide (LDH) Cadnium fluoride, Aluminium Chloride and Rhodamine B.

\section{INTRODUCTION}

Organic dyes used in textile manufacturing are considered to be an essential source of pollutants to the environment due to their non biodegradability and high toxicity to aquatic creatures and carcinogenic effects on humans. Therefore, organic dyes removal from waste waters has been one of the most important environmental issues and complete removal of organic dyes is essential because organic dyes will be perceptible even at low quantities (Papic et al., 2004).

A number of physical and chemical treatment processes including precipitation, adsorption, air stripping, flocculation, reverse osmosis and ultrafiltration are being employed for the removal of these toxic pollutants from water. Most of these methods suffer from various drawbacks (Jeanette et al., 2005). These methods are fairly effective in removing pollutants. However the main drawback of these techniques is formation of secondary waste product which cannot be treated again and dumped as such (Ferreira et al.,2001)

Photocatalysis is being considered as an efficient process for the mineralization of toxic organic dyes, due to the generation of hydroxyl radicals $\left(\mathrm{OH}^{\circ}\right)$ which possess strong oxidizing potential (Arslan et al., 2000).In all known AOPs, the heterogeneous photocatalytic process is the most effective method because of its high availability, low toxicity, inexpensive and diverse nature that might attacked and mineralize a large number of contaminants (Khatee and Kasiri, 2010)

Several studies demonstrated that the group of hydrotalcites, which are layered double hydroxides (LDH) or anionic clays, are efficient materials to intercalate anionic compounds such as sulphate dyes and surfactants, halides, sulfates, nitrates, silicates, chlorides, and polymers (Barriga et al., 2002)

A number of researches have been carried out on photocatalytic degradation of dyes using layered double hydroxide catalysts. Shahid et al., (2016) investigated $\mathrm{Cd}-\mathrm{Al} / \mathrm{C}$ and $\mathrm{Cd}-\mathrm{Sb} / \mathrm{C}$ layered double hydroxides nanocatalyst for the decoloration and mineralization of organic dyes. Ayawei et al., (2017) reported that the ability of $\mathrm{Mg} / \mathrm{Fe}-\mathrm{CO}_{3}$ to degrade Congo Red in aqueous solution was investigated under various experimental conditions. Zhe-Ming et al., (2017) investigated a series of $\mathrm{Zn} / \mathrm{M}-\mathrm{NO}_{3}-\mathrm{LDHs}(\mathrm{M}=\mathrm{Al}$, $\mathrm{Fe}, \mathrm{Ti}$, and $\mathrm{Fe} / \mathrm{Ti}$ ) which was synthesized through two different methods, and their activities for visible-light photocatalytic degradation on Rhodamine $B(R B)$ were tested. In this research work we used $\mathrm{Cd}-\mathrm{Al} / \mathrm{C}$ to degraded Rhodamine $B$. 


\section{MATERIALS AND METHODS Chemicals and Reagents}

All chemicals used in this research work were of analytical grade, and they include; Phosphoric acid (98\% Sigma Aldrich), Cadmium Flouride $\left(\mathrm{CdF}_{2}\right)$ (Sigma Aldrich), Aluminium chloride $\left(\mathrm{AlCl}_{3}\right)$ (Sigma Aldrich), Ethanol (99\%), Sodium hydroxide ( $\mathrm{NaOH})(99 \%$ Sigma Aldrich) and Hydrochloric Acid ( $\mathrm{HCl}$ ) (97\% Sigma Aldrich).

\section{Synthesis of Cd-Al/C-LDH.}

Salts of Cadmium fluoride $\left(\mathrm{CdF}_{2}\right)$ and Aluminium chloride $\left(\mathrm{AlCl}_{3}\right)$ were well mixed in double distilled water and then mixed with activated carbon through co-precipitation method (Khan et al., 2016). Briefly salt of $\mathrm{AlCl}_{3}$ and $\mathrm{CdF}_{2}$ were dissolved thoroughly in double distilled water in $1: 3$ molar ratio. To this reaction mixture, $1 \mathrm{~g}$ of activated carbon was added and well dispersed by continuous stirring with the help of magnetic stirrer. To this mixture freshly prepared $0.1 \mathrm{M}$ $\mathrm{NaOH}$ solutions was added and continuously monitored till $\mathrm{pH}$ 9. After this, the reaction mixture was placed on a hot plate for $6 \mathrm{~h}$ at 60 ${ }^{\circ} \mathrm{C}$ with homogenous stirring. After completion of the reaction the surplus solution is removed and the precipitate was washed three times with $\mathrm{C}_{2} \mathrm{H}_{5} \mathrm{OH}: \mathrm{H}_{2} \mathrm{O}$ mixture (8:2). The resultant product was dried in an oven for overnight at 50 ${ }^{\circ} \mathrm{C}$ and store in clean tube for further characterization.

\section{CHARACTERIZATION OF LDH}

X-ray Diffaraction (XRD), Scanning electron Microscopy (SEM) and Fourier Transform Infrared Spectroscopy (FT-IR) were employed in the characterization of the $\mathrm{Cd}-\mathrm{Al} / \mathrm{C}$ layered double hydroxide.

\section{PHOTOCATALYTIC EXPERIMENT}

In a typical experiment $100 \mathrm{mg}$ of $\mathrm{Cd}-\mathrm{Al} / \mathrm{C}$ was dispersed in $100 \mathrm{~cm}^{3}$ of dye solution having a concentration $3 \mathrm{ppm}$ in a beaker. The above suspension was magnetically stirred for 25 minutes in the dark to obtained adsorptiondesorption equilibrium to eliminate the error due to any initial adsorption effect. This was then irradiated using 500W high-pressure $\mathrm{Hg}$ lamp of intensity $0.0129 \mathrm{w} / \mathrm{m}^{2}$. A $5 \mathrm{~cm}^{3}$ aliquot was taking at 25 minutes interval, centrifuged at 2000rpm prior to absorbance measurement in order to eliminate error due to scattering.

The catalytic activity of Cd-Al/C-LDH was evaluated against the dye under visible light. The effect of operational parameters such as time, catalyst dosage, $\mathrm{pH}$ and concentration were investigated, the \% removal efficiency R.E. (\%) of catalyst was evaluated by using the following equation.

R.E. $(\%)=\left(\frac{C o-C t}{C o}\right) \times 100=\left(\frac{A o-A t}{A o}\right) \times 100$

$\mathrm{C}_{0}$ represents the original concentration of each dye solution at time $=0, \mathrm{Ct}$ is the concentration of dye solution by adding the catalyst after some time $=\mathrm{t}$ as indicated in equation. Similarly, $\mathrm{A}_{0}$ designated the absorbance of the original concentration of the dye solution at time $=0$ and At is the absorbance of dye solution during reaction progress after passing some time $=\mathrm{t}(\mathrm{Li}$ et al., 2008).

\section{RESULTS AND DISCUSSION}

Characterization of Cd-AI/C LDH

$\mathrm{Cd}-\mathrm{Al} / \mathrm{C} \mathrm{LDH}$ was characterized using X-ray Diffaraction (XRD), Scanning electron Microscopy(SEM) and Fourier Transform Infrared Spectroscopy(FT-IR).

\section{X-ray Diffaraction (XRD) of Cd-Al/C LDH}

The crystalline phase of the prepared samples was characterized by XRD analysis.

The XRD pattern of $\mathrm{Cd}-\mathrm{Al} / \mathrm{C}$ is as shown in figure (1).

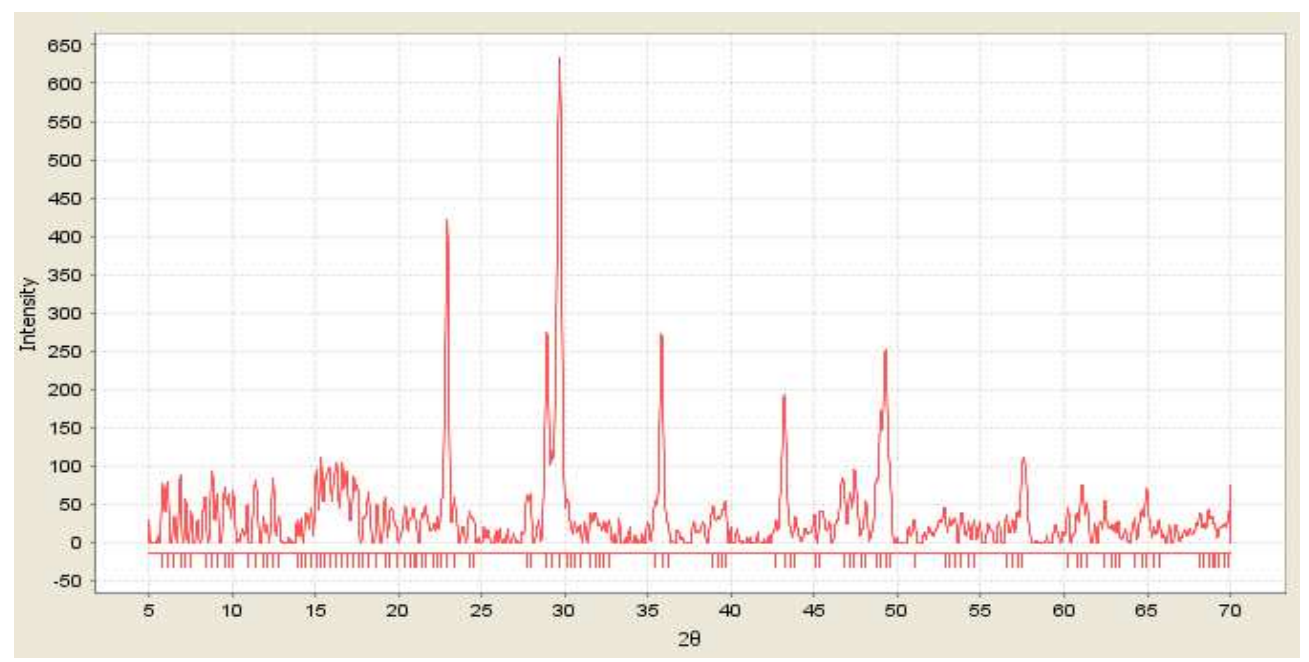

Figure 1: XRD of Cd-Al/C LDH 
The crystalline phases of the Synthesized Cd$\mathrm{Al} / \mathrm{C} \mathrm{LDH}$ was characterized by XRD analysis. Figure 1 display the XRD patterns of the prepared $\mathrm{Cd}-\mathrm{Al} / \mathrm{C} \mathrm{LDH}$. The characteristic peak for $\mathrm{Cd}-\mathrm{Al} / \mathrm{C}$ appeared at $2 \theta=23.4(006)$ and $2 \theta$ $=35.5$ (012) suggesting the formation of $\mathrm{Cd}$ $\mathrm{Al} / \mathrm{C}-\mathrm{LDH}$. The 006 corresponding to the basal reflection of the successive stacking of brucite like layers (El Gaini et al., 2009).The strong diffraction peaks at low angle due to basal planes (006) were sharp and symmetric compared to the peaks at high angle, which are characteristic of clay minerals having a layered structure (Parida et a/ 2006). From figure 1, It can be observe that strong signals in $2 \theta$ range $2-30^{\circ}$. These peaks indicate that the prepared LDHs are characterized by high crystalinity and consistent to great extent, with the peaks of hydrotalcite structure (Ren et al., 2007).

Powder X-rays diffraction (XRD) patterns were recorded with a Thermo scientific XRD machine of model ARL X" TRA with X-ray diffractometer.
The intensities were obtained in the $2 \theta$ ranges between $20^{\circ}$ and $70^{\circ}$. The FULPROF software was used for data handling. FULPROF software allowed estimating the average size of the crystallites. Refinement was performed on the diffraction patterns to determine the crystallite size and relative abundance of phases.

The average crystallite sizes of particles were estimated by the Scherer's formula as shown

$$
D=0.89 \lambda / \beta \cos \theta
$$

Where $D$ is the crystallite size, $\lambda$ is the $X$-ray wavelength, $\beta$ is the broadening of the diffraction

peak and $\theta$ is the diffraction angle for maximum peak. The $D$ value is $101 \mathrm{~nm}$ for $\mathrm{Cd}-\mathrm{Al} / \mathrm{C}$.

Scanning Electron Microscopy (SEM) of CdAl/C

Scanning Electron Microscopy give further insight into the morphology of the $\mathrm{Cd}-\mathrm{Al} / \mathrm{C} \mathrm{LDH}$. The surfaces morphology of $\mathrm{Cd}-\mathrm{Al} / \mathrm{C} \mathrm{LDH}$ is as shown in figure (2).

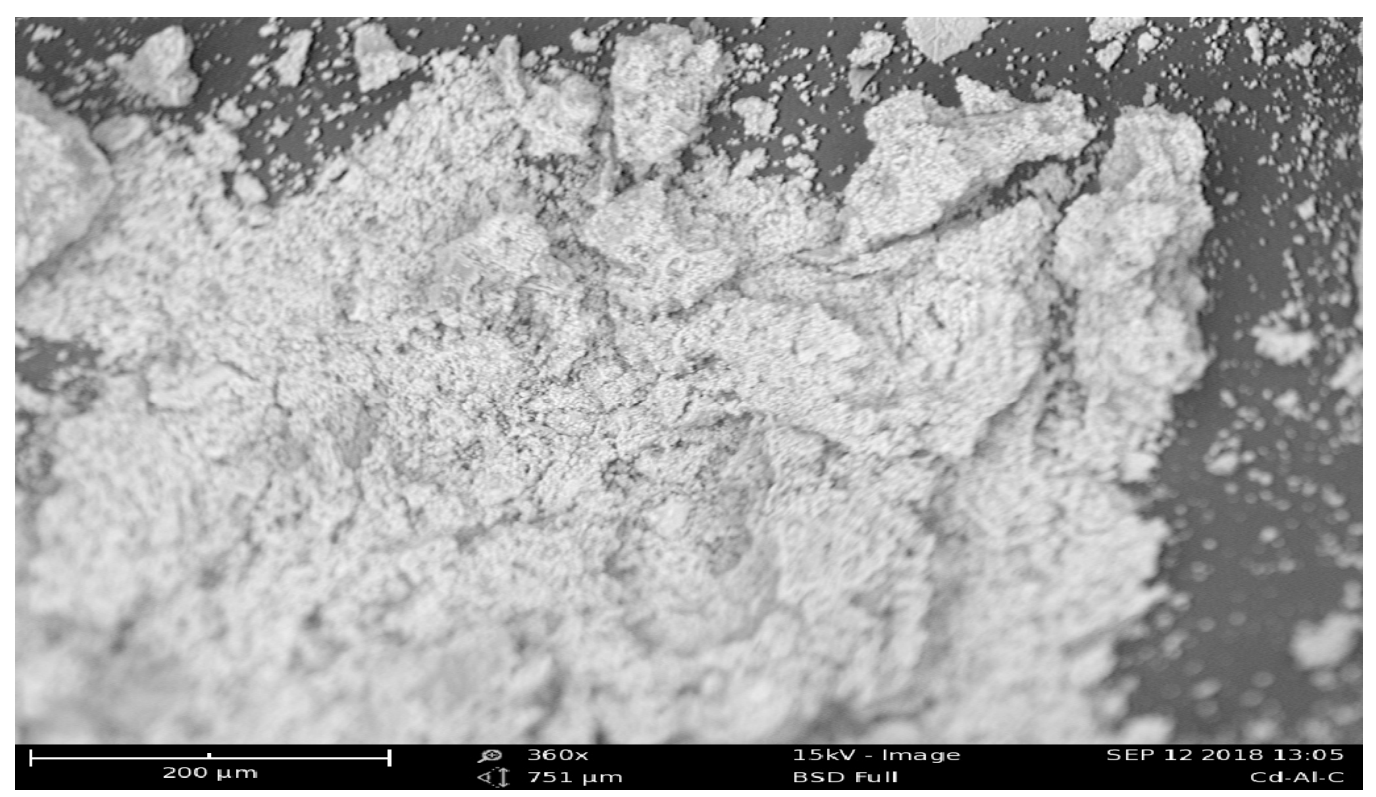

Figure 2 SEM image of Cd-Al/C LDH.

Figure 2 shows the of SEM image for Cd-Al/C LDH. The SEM image shows the sheet morphology of $\mathrm{Cd}-\mathrm{Al} / \mathrm{C}$, which indicate the agglomerated grains are not uniform. The agglomerated pattern is evidence in the formation of LDHs and the morphology of the LDHs are in line with report for LDHs (Hibino and Kobayashi, 2005).

Fourier Transform Infrared Spectroscopy (FT-IR) of Cd-Al/C LDH

FT-IR spectroscopy was used to determine the main functional group responsible for $\mathrm{Cd}-\mathrm{Al} / \mathrm{C}$
LDH formation and other important available functional groups. The FTIR spectra of the prepared $\mathrm{Cd}-\mathrm{Al} / \mathrm{C} \mathrm{LDH}$ is as shown figure (3). 


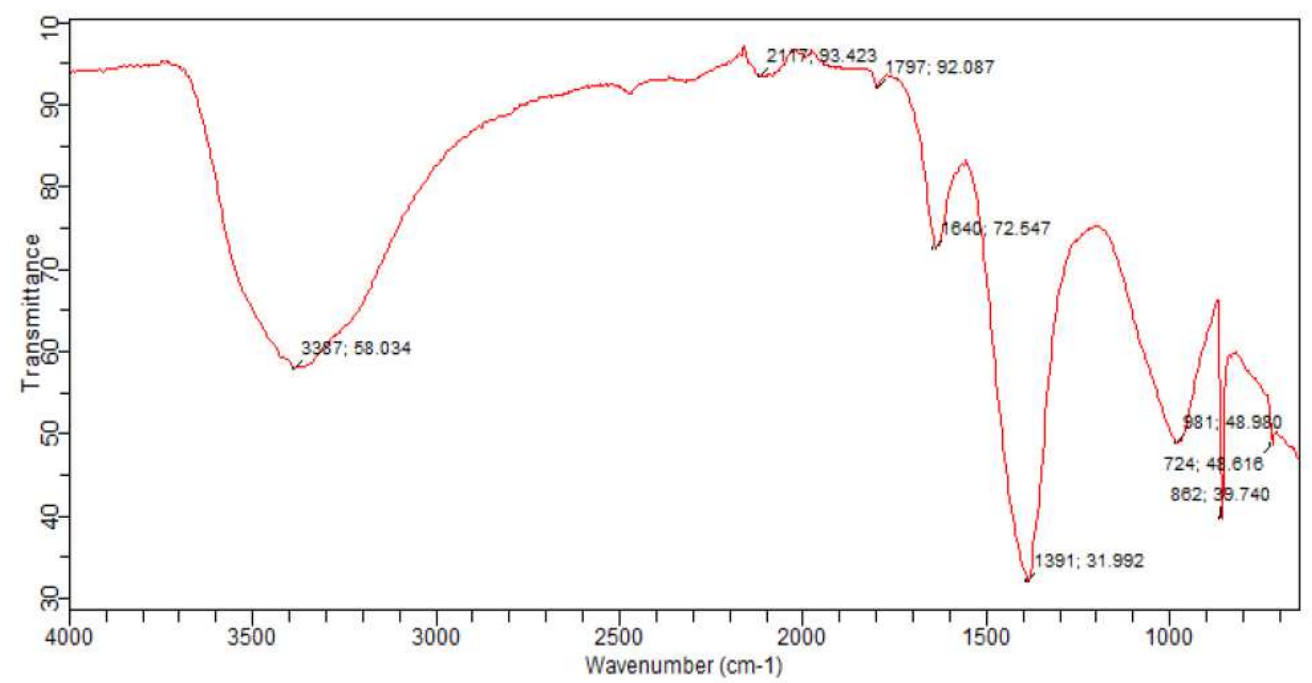

Figure 3: FT-IR Spectrum of Cd-Al/C LDH

The FTIR spectra of the synthesized $\mathrm{Cd}-\mathrm{Al} / \mathrm{C}$ $\mathrm{LDH}$ is represented in figure 3 . The spectra showed a broad absorption band, which is referred to $\mathrm{O}-\mathrm{H}$ stretching mode of the hydroxyl group in the layers, that is found in the region of $3387.58 \mathrm{~cm}^{-1}$. These bands are commonly observed in the LDHs materials (Cavani et al., 1991). At about $1391 \mathrm{~cm}^{-1}$ and there is a characteristic signal of $\mathrm{CO}_{3}{ }^{2-}$ stretching vibrations which is presence in $\mathrm{Cd}-\mathrm{Al} / \mathrm{C}$ (Zhang et al., 2004).The absorption peaks in the low frequency region, for $\mathrm{M}-\mathrm{O}$ is below $862 \mathrm{~cm}^{-1}$ (Tanaka et al ., 2010).

\section{Effect of Operational Parameters}

The effect of operational parameters such as contact time, concentration, catalyst dosage, $\mathrm{pH}$ and temperature, were tested using $\mathrm{Cd}-\mathrm{Al} / \mathrm{C} \mathrm{LDH}$ on degradation Rhodamine $B$ dye.

Effect of Time on Degradation of RB

The effect of time is as shown in figure (4).

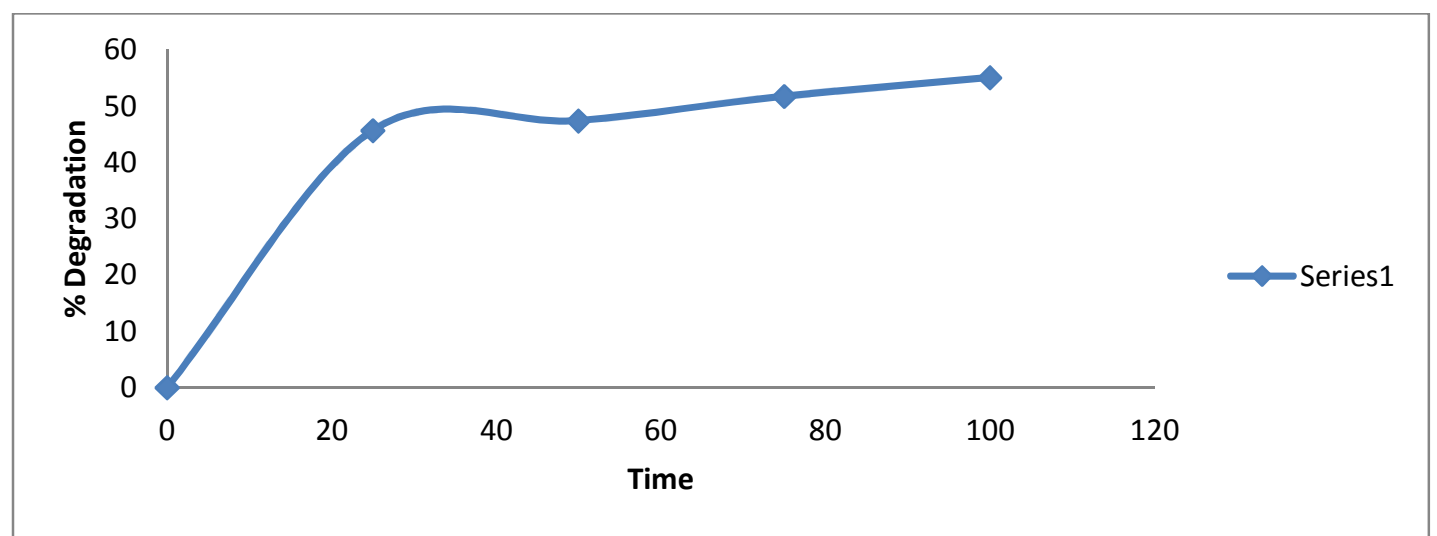

Figure: 4 Effect of time on degradation of RB using Cd-Al/C LDH

From Figure 4, the effect of time on photo degradation of RB was shown, in the presences of $\mathrm{Cd}-\mathrm{Al} / \mathrm{C} \mathrm{LDH}$, it was found after 100min the percentage degradation of RB was increased, the highest percentage was obtained to be $54.91 \%$ This result is in line with the study of Siew et al., (2012) in their study of "Photodegradation of Commercial Dye, Methylene Blue Using Immobilized $\mathrm{TiO}_{2}{ }^{\prime \prime}$.

It is evident that the percentage of removal increases with increasing irradiation time. This is because more $\cdot \mathrm{OH}$ radicals will be generated when the exposure time is longer. The generation of $\bullet \mathrm{OH}$ radicals is crucial in photodegradation process as it oxidizes the organic pollutants to carbon dioxide, water and some simple mineral acids (Siew et al., 2012).

Effect of Catalyst Dosage

The effect of catalyst dosage is as shown in figure (5). 


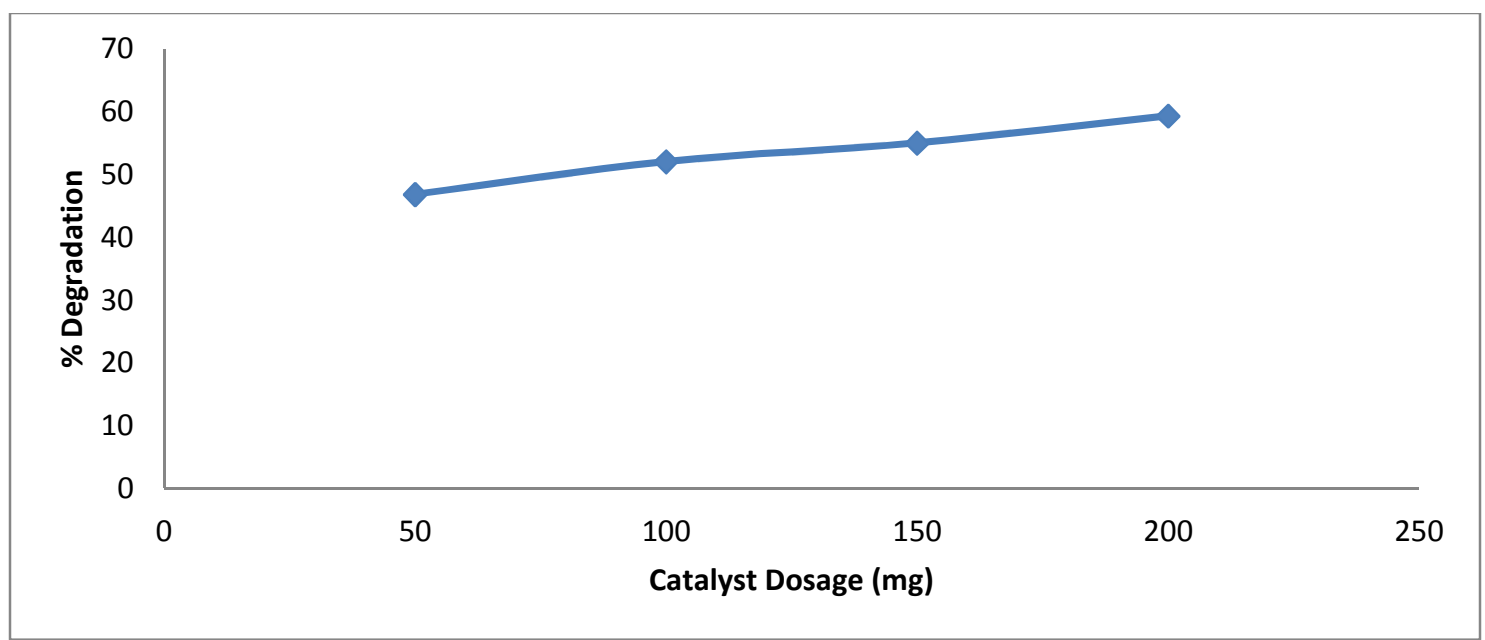

Figure: 5 Effect of catalyst dosage on degradation of RB using Cd-Al/C LDH.

Figure 5 shows the degradation efficiency of RB using $\mathrm{Cd}-\mathrm{Al} / \mathrm{C} \mathrm{LDH}$, with different catalyst dosage after 100min irradiation at neutral $\mathrm{pH}$ condition. The phocatalytic degradation of Rhodamine $B$ increases with increase in the catalyst dosage, the increase was from 46.82$59.32 \%$. This is due to sufficient number of active site on the catalyst surfaces which result in better peneteration of visible light. This result is in line with the results obtained by Jahagir et al., (2014) in their study of 'Photocatalytic degradation of rhodamine $B$ using nanocrystalline $\mathrm{a}-\mathrm{Fe}_{2} \mathrm{O}_{3}$.

\section{Effect of pH}

The effects of $\mathrm{pH}$ is as shown in figure (6).

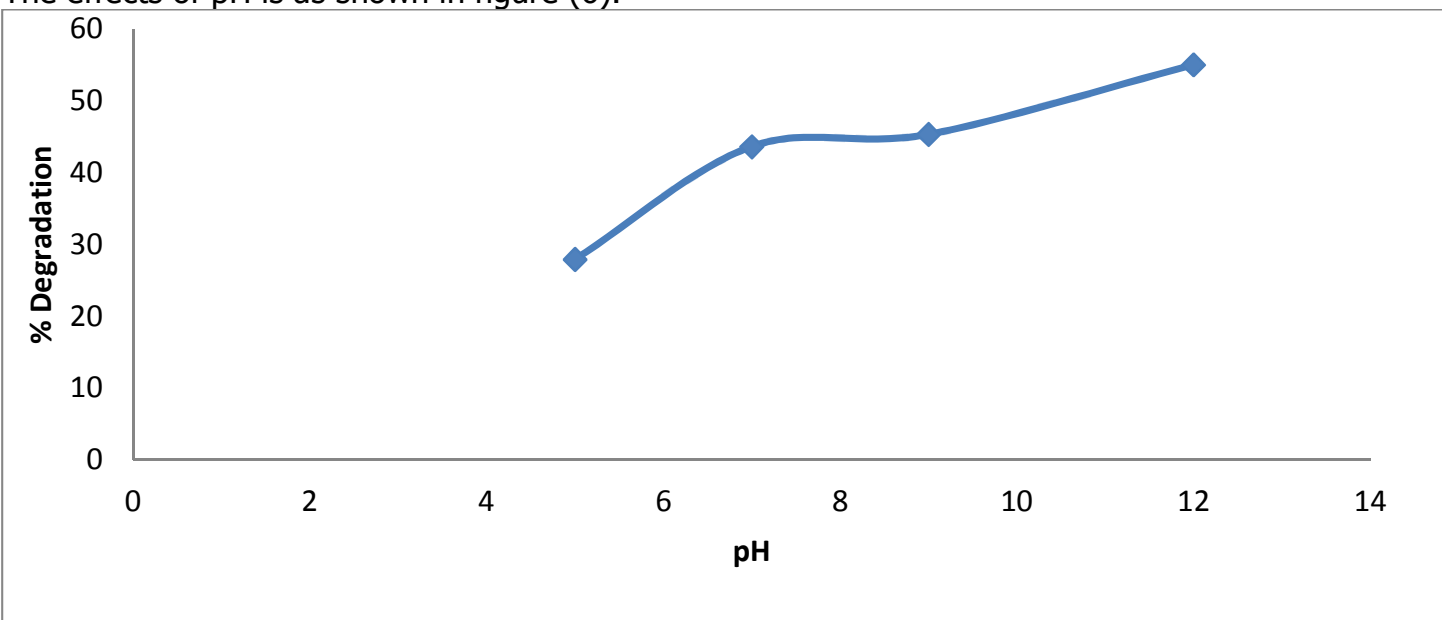

Figure: 6 Effect of $\mathrm{pH}$ on degradation of RB using Cd-Al/C LDH.

The effect of $\mathrm{pH}$ on photocatalytic degradation of $\mathrm{RB}$ by $\mathrm{Cd}-\mathrm{Al} / \mathrm{C}$ is shown in figure 6 . It was observed that the effect of photodegration increase with increase in $\mathrm{pH}$, the increase was from $27.88-55.05 \%$ after $100 \mathrm{~min}$ time of irradiation. This can be due to the increased of hydroxyl ions which induce more hydroxyl radical formation. This result is in agreement with the results obtained by Rakhi and Kishore (2015) in their study of 'Investigation of Photocatalytic Degradation of Rhodamine B by Using Nano-Sized $\mathrm{TiO}_{2 .}$ " 


\section{Special Conference Edition, November, 2019}

\section{Effect of Concentration}

The effects of concentration is as shown in figure (7).

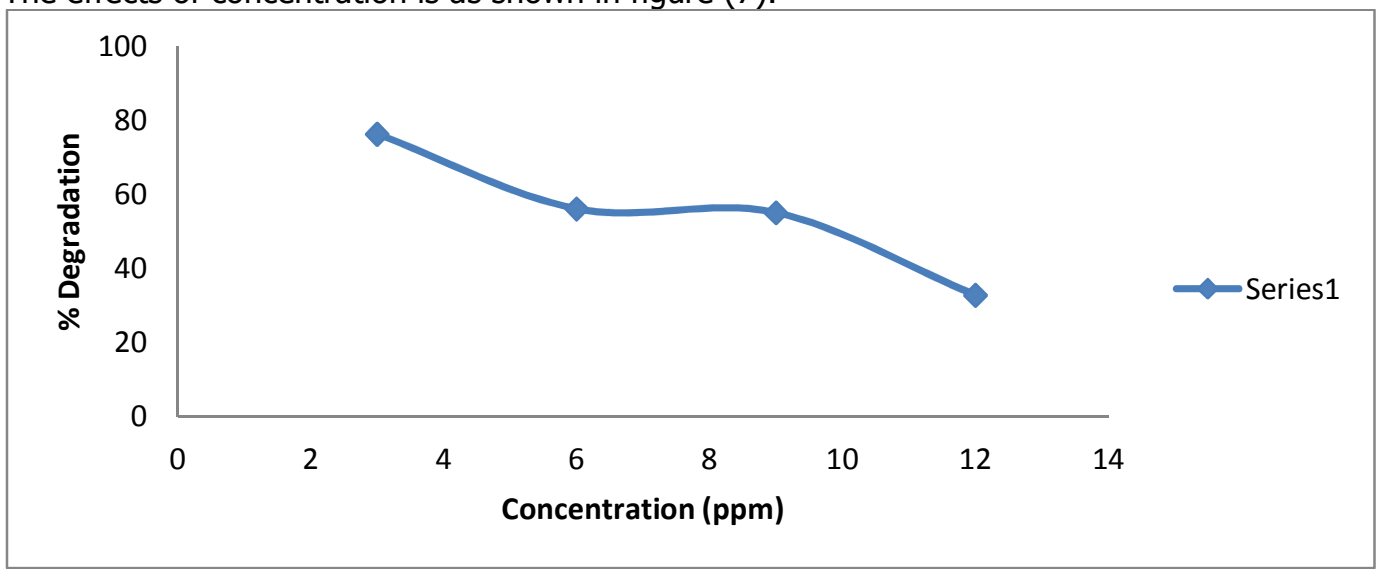

Figure 7: Effect of concentration on degradation of R.B using Cd-Al/C LDH.

Figure 7 shows the effect of concentration on photodegradation of RB was shown, in the presences of $\mathrm{Cd}-\mathrm{Al} / \mathrm{C} \mathrm{LDH}$. It has been observed that the efficiency of photodegradation of rhodamine $B$ tend to decrease with increasing the concentration of dyes, the decrease was from $76.22-32.80 \%$ after $100 \mathrm{~min}$ time of irradiation. which results in decrease in the number of active sites and hence decreasing the production of $\mathrm{OH}$ on the surfaces. This result is in agreement with the results obtained by Rakhi and Kishore (2015) in their study Investigation of "Photocatalytic Degradation of Rhodamine B by Using Nano-Sized $\mathrm{TiO}_{2}$ "

\section{Kinetic Studies}

The degradation of Rhodamine B was carried out and tested kinetically by plotting graphs of the corresponding Pseudo order that is the slope of the graph is equal to $K$ (rate constant) the result summarized and presented in Table ).

Table 1: Kinetic Models and Calculated Parameters on Photodegradation of Rhodamine B using Cd$\mathrm{Al} / \mathrm{C}$.

\begin{tabular}{llll}
\hline DYE & CATALYST & Pseudo First Order & Pseudo Second Order
\end{tabular}

\begin{tabular}{|c|c|c|c|c|c|}
\hline & & $\mathrm{K}$ & $\mathrm{R}^{2}$ & $K$ & $\mathrm{R}^{2}$ \\
\hline Rhodamine B & $\mathrm{Cd}-\mathrm{Al} / \mathrm{C}$ & 0.0209 & 0.890 & 0.04778 & 0.996 \\
\hline
\end{tabular}

The calculated correlation coefficients $\left(R^{2}\right)$ is also close to unity for pseudo-second order kinetic than the other tested kinetic model. Therefore, the adsorption can be approximated more appropriately by pseudo second order kinetic model (Sumanjit et al., 2006).

\section{CONCLUSION}

In this research work, the catalyst (Cd-Al/C) was synthesized by copericipitation method. The catalyst was characterized via X-ray diffaraction (XRD), Fourier infrared spectrophotometer (FTIR) and scanning electron microscope (SEM).

Effects of operational parameters such as contact time, catalyst dosage, initial dye concentration, and effect of $\mathrm{pH}$ were all studied. The experimental results showed that after $100 \mathrm{~min}$ visible light irradiation, the photocatalytic efficiency using $200 \mathrm{mg} \mathrm{Cd}-\mathrm{Al} / \mathrm{C}$, $\mathrm{pH} 7$ and 3ppm Rhodamine B concentration reached to $76.22 \%$.
For kinetics studies the data obtained were modeled using pseudo first order and pseudo second order. From the linear regression coefficient values the data were found to be best fitted to pseudo second order kinetics.

\section{REFERRENCES}

Arslan I., Balcioglu I.A. and Bahnemann D.W. (2000). Advanced Chemical Oxidation of reactive dyes in simulated dye house effuuents by ferrioxalate-fenton/UV-A and $\mathrm{TiO}_{2}$ process Dyes and Pigments. 47(3) 207.

Ayawei, N, Angaye S. S. and Wankasi, D (2017). 'Mg/Fe Layered Double Hydroxide as a Novel Adsorbent for the Removal of Congo red " International Journal of Applied Science and Technology (7)2; 
Barriga, C., Pavlovic, I., Ulibarri, M. A., Hermosin, M. C. and Cornejo, J., (2002). Hydrotalcites as sorbent for 2,4,6trinitrophenol: Influence of the layer composition and interlayer anion. Journal of Materials Chemistry, (12)1027-1034.

Cavani, F. Trifiro, A. Vaccari, (1991) "Hydrotalcite-type anion clays: preparation, properities and applications", Catal. Tod. (11)173.

El-Gain L., Lakarami M., Sebbar E., and Maghea A. (2009) 'Removal of Indigo Carmine dye From Water $\mathrm{Mg}-\mathrm{Al}-\mathrm{CO}_{3}$ Calcined Layered Double Hydroxide'J Hazard Mater (161) 624-632.

Ferreira C, Domenech S, Lacaze P (2001) 'Synthesis and characterization of polypyrrole/TiO2 composites on mild steel" $J$ of Applied Electrochemistry 31(1): 49-56.

Habino T. and Kobayashi M. (2005).'Determination of Layered double Hydroxide in water' Journal of Material Chemistry (15) 653-656.

Jahagir A.A., Zulfiqar M.N., Donappa N., Nagabhushana A., and Nagabhushana B.M. (2014) 'Photocatalytic Degradation of Rhodamine $\mathrm{B}$ Using nanocrystalline $\mathrm{a}-\mathrm{Fe}_{2} \mathrm{O}_{3} \mathrm{~J}$. mater of Environ Sciences, 5(5) 1426-1433.

Jeanette M.C. Robertson, Peter K. J. Robertson, and Linda A. Lawton (2005). A comparison of the effectiveness of $\mathrm{TiO}_{2}$ photocatalysis and UVA photolysis for the destruction of the the destruction of three pathogenic micro-organism. J. Photochem. Photobio. A: Chemistry. 175 (1) (2005) 51.

Khan, S. B., Khan, S. A. \& Asiri, A. M. (2016)'A fascinating combination of $\mathrm{Co}, \mathrm{Ni}$ and $\mathrm{Al}$ nanomaterial for oxygen evolution reaction"Appl.Surf. Sci. (370)445-451.

Khataee, A. \& Kasiri, M. B. (2010). Photocatalytic degradation of organic dyes in the presence of nanostructured titanium dioxide, influence of the chemical structure of dyes. J. Mol. Catal. A: Chem. (328) 8-26.

Li J., S. Liu, and J. Wang (2008) Adsorption and degradation of the cationic dyes over Co doped amorphous mesoporous titania-silica catalyst under UV and visible light irradiation, Microporus Meroporous Material, 115(3) 416-425.

Papic, S., Koprivanac, N., Bozic, A. and Metes, M. (2004) 'Removal of Some Reactive Dyesfrom Synthetic Wastewater by Combined Al(III) Coagulation/Carbon
Adsorption Process" Dyes and Pigments(62) 291-298. https://doi.org/10.1016/S01437208(03)00148

Parida, K. M., Baliarsingh, N., SairamPatra, B. and Das J. (2006). "Copper Phthalocyanine Immobilized $\mathrm{Zn} / \mathrm{Al} \mathrm{LDH}$ as Photocatalyst under Solar Radiation for Decolorization of Methylene Blue."Journal of MolecularCatalysis A: Chemical (267) 202-8.

Rakhi G and Kishore D., (2015) "Investigation Of Photocatalytic Degradation of Rhodamine $\mathrm{B}$ by using Nana Sized $\mathrm{Tio}_{2}{ }^{\prime \prime}$ International Journal of Scientific Research and Management (IJSR) 5 (9) 6006-6013.

Ren N., Charlton J. and Alder P.N. (2007). The flare gene, which encodes the AIPI protein Dros Phila, function to regulate F-action disassembly in popular epidermis cells Genetics 176 (4) 2223-2234

Shahid A. K., Sher B. K., and Abdullahi M. A. (2016).Layered double hydroxide of $\mathrm{Cd}-\mathrm{Al} / \mathrm{C}$ for the Mineralization and De-coloration of Dyes in Solar and Visible Light Exposure.Scientific report, (10) 1038.

Siew T. O., Wai S. C. and Yung T. H. (2012) 'Photodegradation of Commercial Dye, Methylene Blue Using Immobilized $\mathrm{TiO}_{2}{ }^{\prime \prime}$ International Conference on Chemical, Biological and Environmental Engineering (43) 23.

Sumanjit K. Seema R. and Rakesh K.M. (2006) Adsorption Kinetics For Removal of the Hazardous Dye Congo Red by Biowaste material as adsorbents 'Journal of Chemistry (10) 1155.

Tanaka T., S. Nishimoto, Y. Kameshima, J. Matsukawa, Y. Fujita, Y. Takaguchi, M. Matsuda, M. Miyake, (2010) " A novel nanocomposite material prepared by intercalating photoresponsivedendrimers into a layered double hydroxide", J. Solid State Chem. (183) 479.

Zhang X.H., Axton J.M., Drinjakovic J., Lorenz L White-Cooper H. and Renault A.D. (2004) 'Spatial and Temporary Control of Mitotic Cyclins by the Gnu regulator by the embryonic mitosis in Drosophila " J Cell Sci. (16) 3571-3578.

Zhe-Ming N., Sheng-Jie X., Feng-Xian L., JiLong X., and Ping-Ping Q. (2017) ' Layered double hydroxides as efficient photocatalysts for visible-light degradation of Rhodamine B" Journal of Colloid and Interface Science (405) 195-200. 